\title{
Effects of Citrus Sudden Death Disease on Fatty Acid Profile of Orange Tree Bark
}

\author{
Rosilene A. Prestes, ${ }^{a}$ Luiz A. Colnago, ${ }^{\circledR *}{ }^{* b}$ Emanuel Carrilho, ${ }^{\circledR c}$ \\ Nelson R. Antoniosi Filho ${ }^{d}$ and Maria Isabel R. Alves ${ }^{d}$ \\ ${ }^{a}$ Universidade Tecnológica Federal do Paraná (UTFPR), Jardim Carvalho, \\ 84017-220 Ponta Grossa-PR, Brazil \\ ${ }^{b}$ Embrapa Instrumentação, 13560-970 São Carlos-SP, Brazil \\ 'Instituto de Química de São Carlos, Universidade de São Paulo (USP), \\ 13566-590 São Carlos-SP, Brazil \\ ${ }^{d}$ Instituto de Química, Universidade Federal de Goiás (UFG), 74690-900 Goiânia-GO, Brazil
}

\begin{abstract}
Citrus sudden death (CSD) is a disease that has affected millions of orange trees in Brazil, leading to economic losses in the order of billions of US dollars. This article examines the effects of CSD on the fatty acid composition of triacylglycerides (TAG) extracted from rootstock and scion bark. The fatty acid profile determined by gas chromatography showed a reduction in oleic and linolenic acids, and an increase in the saturated fatty acids and linoleic acid content, which was in line with the severity of CSD. The reduction in linolenic acid content was related to its role in the biosynthesis of jasmonic acid, which is involved in responses to abiotic and biotic stresses, as well as senescence. These alterations in the fatty acid profile were also used to classify plants both with and without CSD symptoms by using chemometric means. This method represents an alternative to support the diagnosis of CSD disease.
\end{abstract}

Keywords: plant disease, triacylglycerides, multivariate analysis

\section{Introduction}

Citrus sudden death (CSD) is a citrus disease that is transmitted by graft process or by aerial vector; it has only been detected in Brazil. ${ }^{1,2}$ It has been observed in sweet orange (Citrus sinensis (L.) Osbeck), mandarin trees grafted on rangpur lime (C. limonia Osbeck), and in Citrus volkameriana rootstock. ${ }^{3-5}$ CSD has not been observed in some combinations, e.g., sweet orange with Cleopatra and Sunki tangerine, Poncirus trifoliata and Citrumelo swingle, even in planting near affected orchards. The causal agent is unknown; however, several similarities to Tristeza (quick decline) strongly suggest that CSD is a virus similar to Citrus tristeza virus (CTV). ${ }^{6,7}$ Some researchers ${ }^{4,8}$ have suggested that CSD is caused by a virus similar to CTV or a Marafivirus genus virus (Tymoviridae family). ${ }^{9,10}$

The symptoms of CSD disease start as generalized discoloration and defoliation, symptoms that are also

*e-mail: luiz.colnago@embrapa.br

Editor handled this article: Eduardo Carasek observed in other citrus diseases. The specific symptoms of CSD are observed in the bark, close to the bud union. The bark of CSD-affected plants is thicker than in plants without symptoms, ${ }^{11}$ which is due to a profound anatomical change, and the presence of non-functional phloem. However, the most characteristic CSD symptom is the presence of yellow staining on the bark of the rootstock. CSD destroys the functional phloem, affecting the radicular system and, consequently, affecting the absorption of water and nutrients, $, 3,412$ productivity, and fruit quality. ${ }^{13,14} \mathrm{CSD}$ has caused the eradication of approximately four million sweet orange trees in Brazil.

We recently demonstrated ${ }^{11}$ that CSD can also cause metabolic disorder in citrus tree bark close to the bud union. Nuclear magnetic resonance (NMR) and extraction methods showed an increase in the content of sucrose and triacylglycerides in the bark of CSD-affected plants. ${ }^{11}$ The increase in the sucrose content was statistically significant; from $12.3-15.8 \%$ in the rootstock and from $11-12 \%$ in the scion. The increase in oil content was very high in the bark, rising by 50 and $100 \%$ in the scion and rootstock, respectively, compared with healthy samples 
(control, CON). In CSD-affected plants, the oil content increased from $2-3 \%$ in the rootstock and from $0.5-1 \%$ in the scion in comparison with the CON plants. These variations in oil content were large enough to be used as a complementary method (NMR) to diagnose plants with CSD. ${ }^{11}$

In the present study, we assessed the influence of CSD disease on the fatty acid profile of triacylglycerides (TAG) extracted from rootstock and scion bark samples extracted close to the bud union of Valencia sweet orange trees grafted on rangpur lime. A reduction in linolenic acid content was observed, which may have been related to the biosynthesis of jasmonic acid, which plays a role in responses to abiotic and biotic stresses, as well as senescence. These alterations in the fatty acid profile were used to classify the plants as either being with or without CSD symptoms, by using the soft independent modelling of class analogy (SIMCA) and K-nearest neighbors (KNN) chemometric methods. Therefore, variations in fatty acid profiles can be used as an alternative method to support the diagnosis of CSD disease.

\section{Experimental}

Plant material

Bark from Valencia orange (Citrus sinensis Osbeck), grafted on a rootstock of Rangpur lime (Citrus limonia Osbeck), aged 11 years, was collected in October 2006 in the regions of Gavião Peixoto and Colombia, in orchards situated in the municipalities of Gavião Peixoto and Colombia, São Paulo, Brazil. Gavião Peixoto is located at latitude $21^{\circ} 50$ ' 20 ”' south and longitude $48^{\circ} 29^{\prime} 41^{\prime \prime}$ 'west, at an altitude of 515 meters, while Colombia is located at latitude $20^{\circ} 10^{\prime} 33^{\prime \prime}$ south and longitude $48^{\circ} 41^{\prime} 20^{\prime \prime}$ 'west, at an altitude of 492 meters. The bark was cut $10.0 \mathrm{~cm}$ in length and $3.0 \mathrm{~cm}$ wide, close to the bud union. The rootstock and scion bark were collected from 20 plants without symptoms of CSD (control, CON), and 20 plants with symptoms of CSD, eight of which had mild symptoms (CSD1), and 12 of which had severe symptoms (CSD2). The CSD1 samples were obtained from plants with initial symptoms, characterized by light yellow rootstock bark and foliar discoloration. The CSD2 samples were obtained from plants with severe symptoms, with dark yellow rootstock bark.

The samples taken from the orchard were placed in individual plastic bags and stored in Styrofoam boxes with ice. The samples were milled (Lab House, Wyllie MicroTE-650, Belo Horizonte, MG, Brazil) at the laboratory and the powders were passed through a 16-mesh sieve. The samples were frozen in an ultracooler (Tectalmaq,
Piracicaba, SP, Brazil) and dehydrated in a lyophilizer (Analitica, Epsilon 2-4 LSCplus, São Paulo, SP, Brazil).

Approximately four grams of the samples were placed on Erlenmeyer flasks with $50 \mathrm{~mL}$ of hexane (Synth, São Paulo, Brazil), and then shaken in an orbital shaker (SPLabor, Modelo SP-222, Presidente Prudente, SP, Brazil) at $200 \mathrm{rpm}$ for $72 \mathrm{~h}$. The bark particles were removed by filtration and the oil was obtained after evaporating the solvent in a hood (SPLabor, Modelo SP-60 N, Presidente Prudente, SP, Brazil). All the procedures were performed in triplicate.

\section{Gas chromatography (GC) analysis}

The fatty acid methyl esters (FAME) of the oil were prepared by the transesterification reaction using the procedure described elsewhere. ${ }^{11,15}$ The FAME were analyzed by gas chromatography (GC) using Shimadzu GC-17A equipment combined with a QP 5050A mass spectrometry detector (Baueri, SP, Brazil). The column was an LM-100 (Carbowax 20M, polyethylene glycol fused silica capillary column with $30 \mathrm{~m} \times 0.25 \mathrm{~mm} \times 0.30 \mu \mathrm{m}$ film thickness). The initial oven temperature was $60^{\circ} \mathrm{C}$, which was raised to $220{ }^{\circ} \mathrm{C}$ at $8{ }^{\circ} \mathrm{C} \mathrm{min}{ }^{-1}$, and held for $50 \mathrm{~min}$. Helium was used as the carrier gas with a flow rate of $36.5 \mathrm{~cm} \mathrm{~s}^{-1}$. The injector temperature was $250{ }^{\circ} \mathrm{C}$, and the amount of injection was $1 \mu \mathrm{L}$ at splitless mode (1:10) with a purge-off time of $1 \mathrm{~min}$. The temperature of the gas chromatography-mass spectrometry (GC-MS) transfer line was $250{ }^{\circ} \mathrm{C}$. The MS was operated at $250{ }^{\circ} \mathrm{C}$ with electron ionization $(70 \mathrm{eV})$. The FAME were identified by comparing the elution time with FAME standards purchased from Sigma-Aldrich Chemical (FAME mix C4-C24 unsaturates, Saint Louis, United States).

The relative concentrations of the FAME were obtained with Shimadzu GC-17A equipment using gas chromatography with flame-ionization detection (GC-FID, Baueri, SP, Brazil). The column was Carbowax 20M, with a $30.0 \mathrm{~m} \times 0.25 \mathrm{~mm}$ fused silica capillary column and $0.25 \mu \mathrm{m}$ film thickness. The splitless injection mode was used for an elution volume of $1 \mu \mathrm{L}$. Hydrogen was used as carrier gas and its mean linear velocity was $31.00 \mathrm{~cm} \mathrm{~s}^{-1}$; nitrogen was applied as auxiliary gas at $2.06 \mathrm{~mL} \mathrm{~min}{ }^{-1}$. The temperature at the injector and detector was $250{ }^{\circ} \mathrm{C}$. The initial oven temperature was $60^{\circ} \mathrm{C}$ for $8 \mathrm{~min}$ and the heating rate was $8^{\circ} \mathrm{C}$ min $^{-1}$ until $220^{\circ} \mathrm{C}$. This temperature was kept constant for $50 \mathrm{~min}$.

\section{Multivariate analysis}

Principal component analysis (PCA) ${ }^{16,17}$ is a mathematical method for data compression based on covariations between 
samples that enhances their similarities and differences. It was performed using Infometrix Pirouette 4.0 software. $^{18}$ The relative concentration of each fatty acid (in percentage), obtained by GC-FID, of the 40 scion and 40 rootstock bark samples were analyzed by PCA as a single dataset per plant (rootstock plus scion data) and as two separate datasets (rootstock or scion). The samples were divided into two subgroups: 20 plants without symptoms (CON), and 20 plants with symptoms (CSD). The samples were also divided into three subgroups: 20 plants without symptoms (CON); 12 plants with mild CSD symptoms (CSD1); and eight plants with severe CSD symptoms (CSD2). The data were mean-centered before the PCA.

The same datasets were used for training and validation, using the methodologies of SIMCA ${ }^{19}$ and KNN. ${ }^{20}$ For the two subgroups, 16 and four CON or CSD samples were used for training and validation, respectively. For the three subgroups, the CSD dataset was divided into CSD1 and CSD2 subgroups. Ten CSD1 and six CSD2 samples were used for training, and two CSD1 and two CSD2 samples were used for validation.

\section{Results and Discussion}

Figure 1 shows the concentration of the FAME measured by GC and prepared from the TAG extracted from the samples of bark from scion and rootstock of the citrus tree as a function CSD symptoms level (CON, CSD1 and CSD2). Figure 1a shows the concentration of the minor FAME components of the TAG, which were capric (C) C10:00, lauric (La) C12:00, myristic (M) C14:00, and stearic (S) C18:00 acids. C was the lowest concentration of acid found; less than $0.5 \%$ in all the analyzed samples. $\mathrm{La}$ and $\mathrm{M}$ were found at similar concentrations and varied from $1.1 \%$ in both the scion and rootstock of the CON plants, to $2.5 \%$ in the rootstock bark of the CSD plants. The concentrations of $\mathrm{La}$ and $\mathrm{M}$ increased in the bark samples from the rootstock of the CSD plants, and showed similar concentrations in the scion samples. The concentration of S varied from 2.7-3.5\% and showed small increases in line with CSD symptoms in both the rootstock and scion samples.

Figure $1 \mathrm{~b}$ shows the concentrations of the major FAME components in the samples: palmitic $(\mathrm{P}) \mathrm{C16}$ :00; oleic $(\mathrm{O})$ C18:1n-9; linoleic (L) C18:2n-6; and linolenic (Ln) C18:3n-3 acids. The results demonstrate that $L$ was the most abundant fatty acid in the bark samples. The concentration of this acid increased in line with CSD symptoms, with an average value varying from $32-38 \%$ of FAME. Ln was the second most abundant fatty acid in the rootstock samples, and third in the scion samples. The Ln concentration
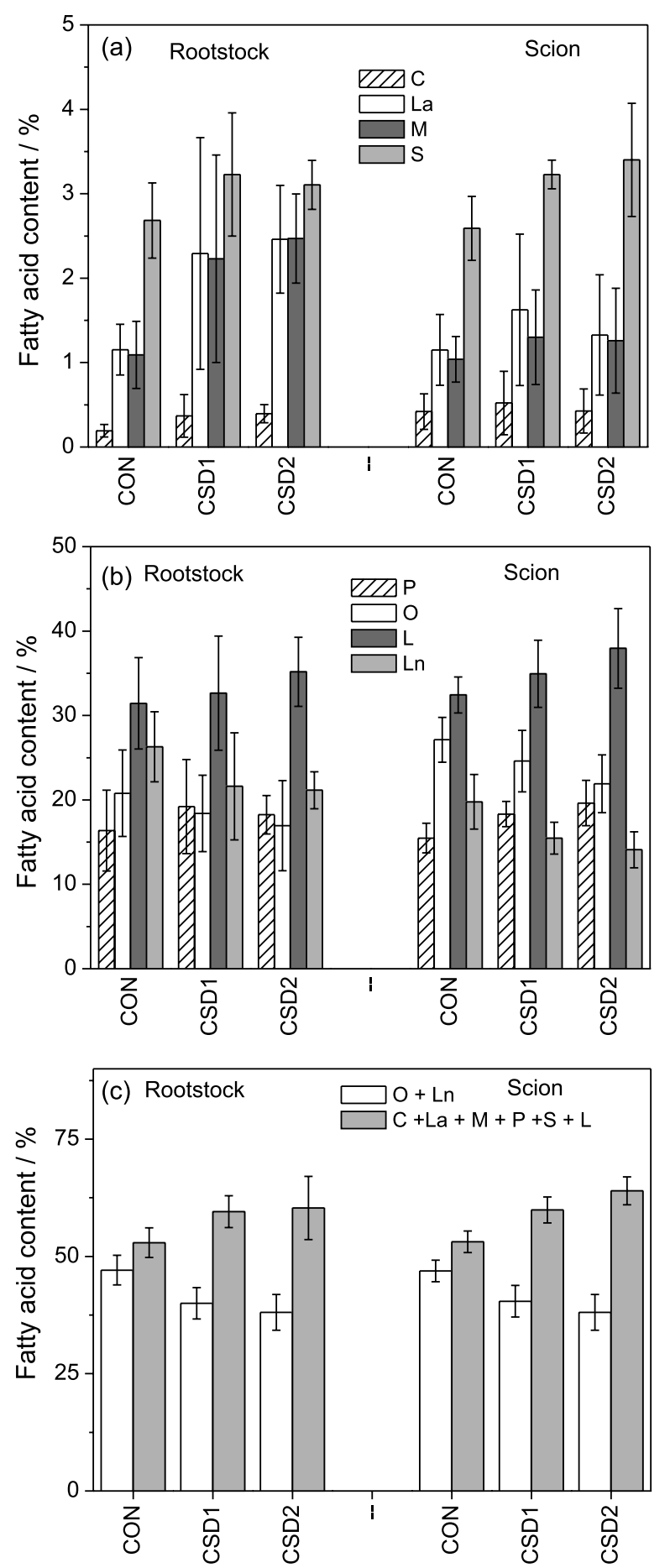

Figure 1. Percentage concentrations of fatty acids: (a) lower concentration: C, La, M and S; (b) higher concentration: P, O, L and Ln of the TAG of CON, CSD1 and CSD2 samples; (c) sum of the concentrations with increased trends $(\mathrm{La}+\mathrm{C}+\mathrm{M}+\mathrm{P}+\mathrm{S}+\mathrm{L})$ and decreased trends $(\mathrm{O}+\mathrm{Ln})$.

declined in line with the CSD symptoms in both the bark samples, varying from $26-21 \%$ in the rootstock samples and from $20-15 \%$ in the scion samples. O was the third most abundant fatty acid in the rootstock samples, and second in the scion samples. Similarly to Ln, the O concentration declined in line with the CSD symptoms in both the bark 
samples, varying from $20-17 \%$ in the rootstock samples, and from $30-23 \%$ in the scion samples. The concentration of $\mathrm{P}$ was similar in both the rootstock and scion samples, and increased from $15-20 \%$.

Therefore, the levels of $\mathrm{O}$ and $\mathrm{Ln}$ decreased in line with the severity of the CSD symptoms, and the concentrations of the other fatty acids increased. This is better seen in Figure 1c, which shows the variation of the concentration of $\mathrm{O}$ and Ln, which decreased, and the sum of the concentration of the other fatty acids, which increased in line with CSD symptoms.

The standard deviations of the FAME with less than $4 \%$ (Figure 1a) are larger because their relative concentration was strongly influenced by the large variation observed in the concentrations of the major fatty acids (Figure 1b).

The effect of the disease on the fatty acid content is unknown. However, one hypothesis is that the decrease in the concentration of $\mathrm{Ln}$ in line with the severity of the CSD symptoms was due to its role in the biosynthesis of jasmonic acid (JA). ${ }^{21,22} \mathrm{JA}$ is involved in plant regulatory mechanisms in response to abiotic and biotic stresses, as well as senescence. The first step in JA biosynthesis is the oxidation of linolenic acid to $(9 Z, 11 E, 15 Z, 13 S)$-13-hydroperoxy9,11,15-octadecatrienoic acid, which is catalyzed by lipoxygenase (LOX). Therefore, the linolenic acid content decreased in the scion and rootstock bark samples because it was used in JA biosynthesis, in response to the infection and hydric stress. The presence of JA may also be involved in one of the first symptoms of CSD disease, generalized foliar discoloration and defoliation. ${ }^{23}$ Therefore, the decrease of $\mathrm{O}$ and increase of $\mathrm{L}$ may have been related to Ln biosynthesis. In plants, linolenic acid is synthesized from oleic acid, via linoleic acid, which is catalyzed by desaturase.

Because CSD altered the fatty acid composition in the bark samples, chemometric methods were used to evaluate if these variations could be used to discriminate between the plants with CSD symptoms (CSD1 and CSD2), and those without symptoms (CON).

\section{Chemometric analysis}

The concentration of each of the eight fatty acids obtained from the gas chromatograms of 40 scion and 40 rootstock bark samples were analyzed as a single dataset per plant (rootstock plus scion data), and also as two separate groups (rootstock or scion) by PCA. The samples were also divided into three subgroups; CON (20), CSD1 (12) and CSD2 (8). The PCA analysis of the rootstock plus scion samples, and the rootstock and scion data sets (mean-centered), explained more than $99 \%$ of the variance using the first three principal components (PC).
Figure 2 shows the score and loading plots for PC1 $(52.28 \%)$ versus PC2 $(27.78 \%)$ for the fatty acid composition data set of the rootstock plus scion samples. The score plot (Figure 2a) shows that the CON (filled circle) and CSD (open symbols) samples were discriminated on the PC2 axis. Most of the CON plants were on the positive side of the PC2 axis and the symptomatic ones were on the negative side. The score plot also shows some discrimination between the plants with mild symptoms (CSD1) and those with severe symptoms (CSD2). The CSD1 samples were at approximately zero to negative PC2 values, and the CSD2 samples showed more negative values. The score plot between PC1 and PC3 (data not shown) was similar to PC1/PC2, without separation on PC1 and with a small separation on the PC3 axis.

The loading plot (Figure 2b) shows that the Ln and $\mathrm{O}$ fatty acids, which decreased in line with the severity of CSD symptoms, were on the positive side of PC2. The other fatty acids, which increased in line with CSD symptoms, were on the negative side of PC2.
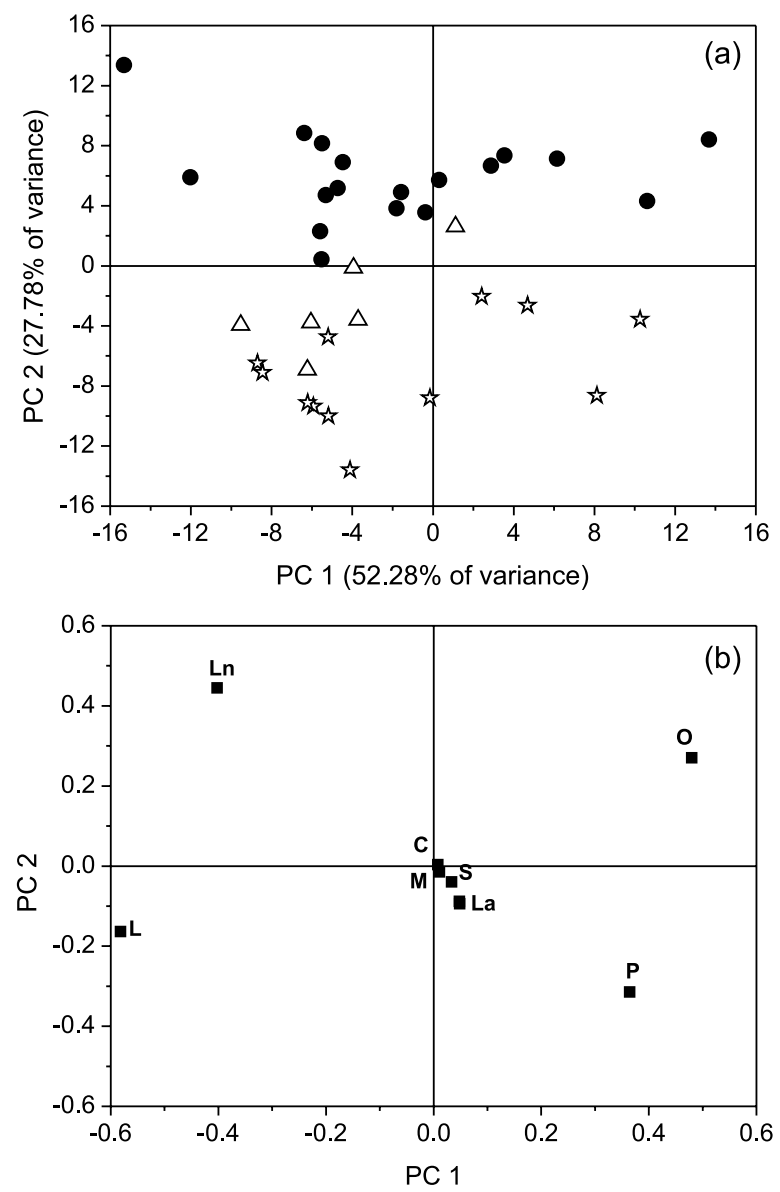

Figure 2. Scores and loading plots of the principal components analysis of the data set of the concentration of fatty acids extracted from the bark of rootstock plus scion samples of orange plants without CSD symptoms (CON- $)$, and with CSD symptoms (CSD1- to and CSD2- $\triangle$ ). (a) PC1 versus PC2 score plot. (b) PC1 versus PC2 loading plot. 
Figure 3 shows the score plots for the rootstock and scion samples. Figure 3a shows the PC1 (71.31\%) versus PC2 (22.20\%) for the fatty acid composition dataset of the rootstock samples, and Figure $3 \mathrm{~b}$ shows the fatty acid composition dataset for the scion samples. The PCA results for the rootstock samples were similar to the results observed for the rootstock plus scion samples data set (Figure 2), with discrimination on PC2. Conversely, the discrimination for the scion samples data set was on PC1 $(56.02 \%)$, and there was no discrimination on PC2 (35.39\%). This exploratory PCA demonstrated that the fatty acid dataset of the rootstock samples (Figure 3a) contained more information to discriminate between the CON and CSD samples than the scion samples dataset. This may have been related to the higher amount of TAG in the rootstock bark than the scion bark, ${ }^{11}$ as well as the fact that rootstock bark can be more affected by CSD than scion bark. Normally, yellow staining on rootstock bark is the most important symptom to identify plants with CSD. Therefore, it was possible to use the PCA of the
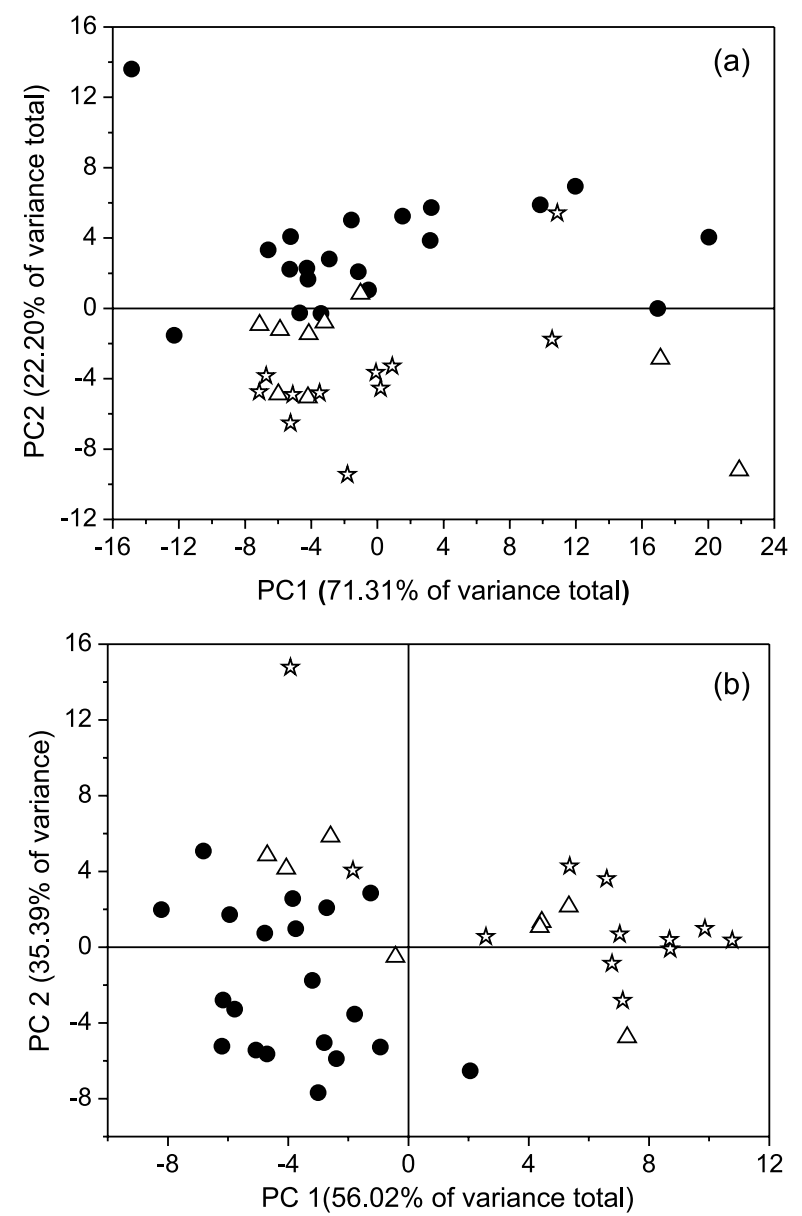

Figure 3. Score plot of the principal component analysis of the data set of the concentration of the fatty acids extracted from the bark of rootstock (a) and scion (b) samples from orange plants without CSD symptoms $(\mathrm{CON}-\bullet)$ and with CSD symptoms (CSD1- tr and CSD2- $\triangle$ ). rootstock fatty acids (Figure 3a) to discriminate between plants with and without CSD disease, with almost the same discrimination power of the dataset of the rootstock plus scion samples (Figure 2a).

The fatty acid composition of the rootstock plus scion samples, and the rootstock samples and the scion samples, were also used to classify the samples by utilizing the SIMCA and KNN methods. The classification models were performed using cross-validation, with one leave-out sample procedure.

Table 1 shows the percentage of correctly predicted samples in the training and validation process divided into two categories (CON and CSD) using the fatty acid dataset of the rootstock plus scion samples. This table shows that SIMCA classified $100 \%$ of the CON or CSD samples in the correct category in both the training and validation datasets. The KNN prediction was $100 \%$ for CON for both the training and validation datasets, and 88 and $75 \%$ for CSD in relation to the training and validation datasets, respectively.

Table 1. Percentages of modeling classification for rootstocks plus scions samples, with $95 \%$ confidence

\begin{tabular}{lcccccc}
\hline \multirow{2}{*}{ Class } & \multicolumn{2}{c}{ SIMCA prediction / \% } & & \multicolumn{2}{c}{ KNN prediction / \% } \\
\cline { 2 - 3 } \cline { 5 - 6 } & Training set & Validation set & & Training set & Validation set \\
\hline CON & 100.0 & 100.0 & & 100.0 & 100.0 \\
CSD & 100.0 & 100.0 & & 88.0 & 75.0 \\
CSD1 & 83.3 & 100.0 & & 33.3 & 50.0 \\
CSD2 & 90.0 & 100.0 & & 80.0 & 50.0 \\
\hline
\end{tabular}

CSD: citrus sudden death; CON: without symptoms of CSD; CSD1: mild symptoms of CSD; CSD2: severe symptoms of CSD; SIMCA: soft independent modelling of class analogy; KNN: k-nearest neighbors.

When the samples were divided into three categories (CON, CSD1 and CSD2) the predictions for the CON samples were $100 \%$ using SIMCA or KNN. The predictions for the CSD1 and CSD2 samples were better than $83.3 \%$ for SIMCA, and only better than $33.3 \%$ for KNN. These results indicate that the SIMCA model was only most efficient to classify the CSD symptoms at two levels than KNN. It also confirms that the fatty acid disorders in the bark of the citrus plant (rootstock and scion) were strongly linked to CSD symptoms.

The same study was performed using the rootstock or scion sample datasets. Table 2 shows the percentage of correctly predicted samples, which were divided into two categories (CON and CSD) using the scion or rootstock sample datasets. The correct predictions were higher than $75 \%$ for the training and validation datasets using SIMCA, and higher than $69 \%$ for KNN. This result demonstrates that SIMCA was a better method to classify plants both with and without CSD symptoms. 
Table 3 shows the classification into the three groups using rootstock or scion samples. The correct predictions were 100 and $81.25 \%$ for $\mathrm{CON}$ for the rootstock samples, using SIMCA and KNN, respectively. However, both the SIMCA and KNN predictions showed a very high dispersion in the correct predictions for the CSD1 or CSD2 samples in relation to both rootstock and scion samples. This problem may have been related to the small number of CSD1 and CSD2 samples in the dataset.

Table 2. Percentages of classification and validation of modeling for rootstock and scion samples for two categories, with $95 \%$ confidence

\begin{tabular}{lccc}
\hline Class & Region & SIMCA / \% & KNN / \% \\
\hline \multirow{2}{*}{ CON } & scion & 94.0 & 94.0 \\
& rootstock & 94.0 & 81.3 \\
\hline \multirow{2}{*}{ CSD } & scion & 75.0 & 94.0 \\
& rootstock & 87.5 & 69.0 \\
\hline
\end{tabular}

CSD: citrus sudden death; CON: without symptoms of CSD; SIMCA: soft independent modelling of class analogy; KNN: k-nearest neighbors.

Table 3. Percentages of classification and validation of modeling for rootstock and scion samples for three categories, with $95 \%$ confidence

\begin{tabular}{lccc}
\hline Class & Region & SIMCA / \% & KNN / \% \\
\hline \multirow{2}{*}{ CON } & scion & 81.3 & 94.0 \\
& rootstock & 100.0 & 81.25 \\
\hline \multirow{2}{*}{ CSD1 } & scion & 100.0 & 83.3 \\
& rootstock & 100.0 & 33.3 \\
\hline \multirow{2}{*}{ CSD2 } & scion & 70.0 & 70.0 \\
& rootstock & 60.0 & 60.0 \\
\hline
\end{tabular}

CSD: citrus sudden death; CON: without symptoms of CSD; CSD1: mild symptoms of CSD; CSD2: severe symptoms of CSD; SIMCA: soft independent modelling of class analogy; KNN: k-nearest neighbors.

\section{Conclusions}

Given these results, we can conclude that CSD disease significantly altered the fatty acid profile in the bark samples from the rootstocks and scions. This disorder may be related to the synthesis of jasmonic acid, from linolenic acid, which is related to plant defense mechanisms, and to several symptoms of plants with CSD, such as foliar discoloration and defoliation. ${ }^{1}$ Therefore, alterations in fatty acid profiles can be used to classify plants both with and without CSD symptoms by using chemometric methods such as SIMCA and KNN. This classification represents an alternative method to support the diagnosis of CSD disease.

\section{Supplementary Information}

Supplementary information is available free of charge at http://jbcs.sbq.org.br as PDF file.

\section{Acknowledgments}

We wish to thank the Brazilian agencies FAPESP, CNPq (302866/2017-5), and FINEP for financial support, and Dr Nelson Arno Wulff for supplying the bark samples. This study was financed in part by the Coordenação de Aperfeiçoamento de Pessoal de Nível Superior - Brasil (CAPES) - Finance Code 001.

\section{References}

1. Yamamoto, P. T.; Bassanezi, R. B.; Wulff, N. A.; Santos, M. A.; Toloy, R. S.; Gimenes-Fernandes, N.; Ayres, A. J.; Jesus, W. C.; Nagata, T.; Tanaka, F. A. O.; Kitajima, E. W.; Bove, J. M.; Plant Dis. 2011, 95, 104.

2. Pompeu, J.; Blumer, S.; Rev. Bras. Frutic. 2008, 30, 1159.

3. Bassanezi, R. B.; Bergamim, A.; Amorim, L.; GimenezFernandes, N.; Gottwald, T. R.; Bové, J. M.; Phytopathology 2003, 93, 502.

4. Maccheroni, W.; Alegria, M. C.; Greggio, C. C.; Piazza, J. P.; Kamla, R. F.; Zacharias, P. R. A.; Barjoseph, M.; Kitajima, E. W.; Assumpção, L. C.; Camarotte, G.; Cardozo, J.; Casagrande, E. C.; Ferrari, F.; Franco, S. F.; Giachetto, P. F.; Girasol, A.; Jordão, H.; Silva, V. H. A.; Souza, L. C. A.; Aguilarvildoso, C. I.; Zanca, A. S.; Arruda, P.; Kitajima, P.; Reinach, F. C.; Ferro, J. A.; da Silva, A. C. R.; J. Virol. 2005, 79, 3028.

5. Roman, M.; Cambra, M.; Juarez, J.; Moreno, P.; Vila, N. D.; Tanaka, F. A. O.; Alves, E.; Kitajima, E. W.; Yamamoto, P.; Bassanezi, R. B.; Plant Dis. 2004, 88, 453.

6. Rivas-Valencia, P.; Loeza-Kuk, E.; Mora-Aguilera, G.; Febres, V.; Ochoa-Martinez, D.; Gutierrez-Espinosa, M. A.; de Jesus-Junior, W. C.; Correia-Malvas, C.; Wulff, N. A.; Agrociencia 2008, 42, 85.

7. Bové, J. M.; Ayres, A. J.; IUBMB Life 2007, 59, 346.

8. Gomes, C. P. C.; Nagata, T.; de Jesus Jr., W. C.; Borges Neto, C. R.; Pappas Jr., G. J.; Martin, D. P.; Virol. J. 2008, 5, 9.

9. Fadel, A. L.; Mourão Filho, F. A. A.; Stuchi, E. S.; Wulff, N. A.; Couto, H. T. Z.; Rev. Bras. Frutic. 2018, 40, e-788.

10. Matsumura, E.; Coletta-Filho, H.; Machado, M. A.; Nouri, S.; Falk, B.W.; Mol. Plant Pathol. 2019, 20, 611.

11. Prestes, R. A.; Colnago, L. A.; Forato, L. A.; Carrilho, E.; Bassanezi, R. B.; Wulff, N. A.; Mol. Plant Pathol. 2009, 10, 51.

12. Batista, L.; Bassanezi, R. B.; Laranjeira, F. F.; Trop. Plant Pathol. 2008, 33, 348.

13. Bassanezi, R. B.; Montesino, L. H.; Sanches, A. L.; Spósito, M. B. Stuchi, E. S.; Barbosa, I. C.; Plant Dis. 2007, 91, 1407.

14. Bassanezi, R. B.; Busato, L. A.; Sanches, A. L.; Barbosa, J. C.; Fitopatol. Bras. 2005, 30, 497.

15. Hartman, L.; Lago, R. A. C.; Lab. Pract. 1973, 22, 475.

16. Beebe, K. B.; Pell, R. J.; Seasholtz, M. B.; Chemometrics: A Practical Guide; John Wiley \& Sons: New York, USA, 1998, p. 360 . 
17. Llorent-Martínez, E. J.; Domínguez-Vidal, A.; Rubio-Domene, R.; Pascual-Reguera, M. I.; Ruiz-Medina, A.; Ayora-Cañada, M. J.; Microchem. J. 2014, 115, 11.

18. Pirouette 4.0; Infometrix, Inc., Bothel, WA, USA, 2009.

19. Escandar, G. M.; Damiani, P. C.; Goicoechea, H. C.; Olivieri, A. C.; Microchem. J. 2006, 82, 29.

20. Kucharska-Ambrożej, K.; Karpinska, J.; Microchem. J. 2020, $153,10427$.
21. Blouin, M.; Zuily-Fodil, Y.; Pham-Thi, A. T.; Laffray, D.; Reversat, G.; Pando, A.; Tondoh, J.; Lavelle, P.; Ecol. Lett. 2005, 8, 202.

22. Lee, S. H.; Ahn, S. J.; Im, Y. T.; Cho, K.; Chung, G. C.; Cho, B. H.; Han, O. L.; Biochem. Biophys. Res. Commun. 2005, 330, 1194.

23. He, Y.; Fukushige, H.; Hildebrand, D. F.; Gan, S.; Plant Physiol. 2002, 128,876 . 